\title{
High Performance Anti-Reflection Coatings for Broadband Multi-Junction Solar Cells
}

$\begin{array}{ll}\text { Author: } & \text { Daniel J. Aiken } \\ \text { Affiliation: } & \text { Sandia National Laboratories , Albuquerque, NM, } 87185 \\ \text { Phone: } & \text { (505) 284-6607 } \\ \text { Fax: } & \text { (505) 844-6541 } \\ \text { Email: } & \text { djaiken@sandia.gov }\end{array}$

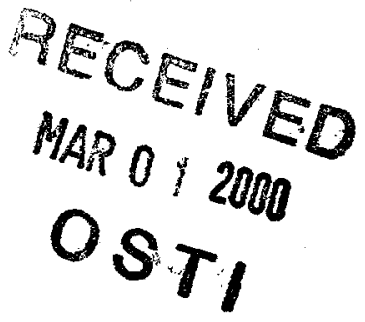

\section{ABSTRACT}

The success of bandgap engineering has made high efficiency broadband multi-junction solar cells possible with photo-response out to the band edge of $\mathrm{Ge}$. Modeling has been conducted which suggests that current double layer anti-reflection coating technology is not adequate for these devices in certain cases. Approaches for the development of higher performance anti-reflection coatings are examined. A new AR coating structure based on the use of Herpin equivalent layers is presented. Optical modeling suggests a decrease in the solar weighted reflectance of over $2.5 \%$ absolute as a result. This structure requires no additional optical material development and characterization because no new optical materials are necessary. Experimental results and a sensitivity analysis are presented.

Keywords: $\quad$ antireflection coating, multi-junction, solar weighted reflectance, Herpin equivalent layers

\section{INTRODUCTION}

Group III-V multi-junction solar cells have achieved world record efficiencies for monolithic, two terminal devices [1]. Dual junction InGaP/GaAs solar cells have reached an AM0 efficiency of $26.9 \%\left(4 \mathrm{~cm}^{2}\right)$ [2]. Triple junction InGaP/GaAs/Ge devices with an AMO efficiency of $26.7 \%\left(21.65 \mathrm{~cm}^{2}\right)$ have also been reported [3]. These multi-junction solar cells are in production at three major space photovoltaics manufacturing companies in the U.S. and are also appealing candidates for use in terrestrial concentrator systems due to their high efficiencies. As a result of this success there is considerable interest in furthering this concept with the development of a $1 \mathrm{eV}$ material lattice matched to GaAs and Ge to make ultra-high efficiency 4-junction solar cells possible $[4,5]$.

Multiple bandgap solar cells convert a larger range of the solar spectrum to electric power as compared to single bandgap solar cells, and have significantly higher limiting efficiencies as modeled by Henry [6]. The larger spectral range of these devices also requires a more broadband antireflection (AR) coating. Reflection control for traditional single junction solar cells such as silicon, GaAs and InP, and even dual junction solar cells such as AIGaAs/GaAs or InGaP/GaAs, has been adequately achieved using relatively simple double layer interference coatings. This is possible due to the relatively narrow spectral range of these solar cells. With the emergence of multi-junctions based on photovoltaically active Ge substrates, the spectral range of multi-junctions has approximately doubled. Additionally, series interconnected multi-junctions place greater demands on AR coating performance due to the need for current matching. This requires a reevaluation of what AR coating performance is necessary and what technologies will provide this level of performance for these solar cells.

Several general approaches for improving the control of reflection at the front surface of a solar cell are possible. Reflection control has been accomplished through the use of macroscopic and microscopic surface texture [7-9], although mainly in silicon solar cell technology. Graded- or gradient-index concepts are also appealing for potentially very high performance $A R$ coatings and have been used mainly on glass substrates thus far [10-12]. This paper focuses on the use of planar, homogeneous optical interference films

- Sandia is a multi-program laboratory operated by Sandia Corporation, a Lockheed Martin Company, for the U.S. Department of Energy under contract DE-AC04-94AL85000. 


\section{DISCLAIMER}

This report was prepared as an account of work sponsored by an agency of the United States Government. Neither the United States Government nor any agency thereof, nor any of their employees, make any warranty, express or implied, or assumes any legal liability or responsibility for the accuracy, completeness, or usefuiness of any information, apparatus, product, or process disclosed, or represents that its use would not infringe privately owned rights. Reference herein to any specific commercial product, process, or service by trade name, trademark, manufacturer, or otherwise does not necessarily constitute or imply its endorsement, recommendation, or favoring by the United States Government or any agency thereof. The views and opinions of authors expressed herein do not necessarily state or reflect those of the United States Government or any agency thereof. 


\section{DISCLAIMER}

Portions of this document may be illegible in electronic image products. Images are produced from the best available original document. 
for reflection control. The step-down interference coating structure $\left(n_{s}>n 1>n 2>n 3>n_{m}\right.$, where $n_{s}$ and $n_{m}$ are the substrate and incident medium refractive indices, respectively) is an effective means of broadband reflection control for high index substrates including solar cells. The effectiveness of various step-down AR coatings is evaluated for several monolithic III-V multi-junction solar cells that are either presently feasible (3junction In $\mathrm{GaP} / \mathrm{GaAs} / \mathrm{Ge}$ ) or will potentially be available in the future (4-junction). The design of a triple layer AR coating is considered as an extension of the presently used double layer coating technology. A new AR coating structure is presented which can achieve a level of performance similar to that of a triple layer AR coating using the same materials that are presently used in conventional double layer AR coatings. Expected performance gains and a sensitivity analysis for this new AR coating will also be presented.

\section{PERFORMANCE MODELING FOR HIGH EFFICIENCY SOLAR CELL AR COATINGS}

Figure 1 shows the spectral range of silicon, dual junction InGaP/GaAs, and hypothetical 4-junction solar cell technologies, i.e. the portion of the wavelength spectrum that each of these technologies converts to electrical energy. Also shown in Figure 1 are the modeled reflectances of a simplified, glass encapsulated solar cell structure with non-dispersive refractive indices. Four different step-down antireflection coatings are used in the model, including single, double, triple, and quadruple layer anti-reflection coatings (SLAR, DLAR, TLAR, and QLAR, respectively). Each coating assumes layers with ideal refractive indices $\left(n_{\text {ideal }}=\left(n_{T}^{*} n_{B}\right)^{3 / 2}\right.$, where $n_{T}$ and $n_{B}$ are the refractive indices of the layers adjacent to the layer in question) and optical thicknesses of a quarter wavelength at $600 \mathrm{~nm}$. The minimum reflectance achievable from this optical system is $3.5 \%$ due to reflection at the uncoated air-glass surface. The glass encapsulant is considered optically thick.

It is evident from Figure 1 that DLAR coatings have an anti-reflective bandwidth that appears wide enough for both the silicon and dual junction InGaP/GaAs solar cell technologies. This is further illustrated using Figure 2, where the modeled reflectances of Figure 1 were used to calculate a solar weighted reflectance (SWR) for each device structure/AR coating pair using the equation

$$
S W R=1-\left(\frac{J_{s c}}{\left.J_{s c}\right|_{R(\lambda)=0}}\right) \text {, }
$$

which is equivalent to the to the solar weighted reflectance as first presented by Redfield [13]. The device short circuit current Jsc used in Equation 1 was calculated using the expression

$$
J_{s c}=q \int_{\lambda} F(\lambda) \cdot I Q E_{\min }(\lambda) \cdot[1-R(\lambda)] d \lambda
$$

which couples the multi-junction short circuit current to the device reflectance as described elsewhere [14].

It is evident from Figure 2 that the SWR of the single or dual junction solar cells discussed here are only marginally higher than the $3.5 \%$ reflectance that is attributed to the air/glass reflectance. The minimal performance increase that is achieved by using more complicated AR coatings is not worth the added device complexity and processing time that would result. Manufacturers of the InGaP/GaAs solar cell therefore use a DLAR coating consisting of $\mathrm{Al}_{2} \mathrm{O}_{3}$ on $\mathrm{TiO}_{2}$. The optically thin window layer used in these devices also functions as a moderately effective third layer in the optical stack, but in this paper is treated as a fixed component of the device structure and not part of the AR coating.

The triple junction In GaP/GaAs/Ge cell has a spectral range equal to that of the 4-junction cell because $\mathrm{Ge}$ is used as the bottom cell in both devices. From an AR coating perspective, however, the triple junction is only slightly more demanding than the dual junction due to the over $25 \mathrm{mAvcm}$ of excess short circuit current that the Ge subcell is theoretically capable of generating. This large current mismatch implies that the Ge subcell can lose a significant fraction of its spectral allotment due to reflection without decreasing the multi-junction Jsc. Reflection loss within the $\mathrm{Ge}$ subcell spectral range affects the multi-junction performance only due to the lower order dependence of Voc on current generation through the equation 


$$
\Delta V_{o c} \approx \frac{k T}{q} \ln \left(\frac{\Delta J s c}{J s c}\right)
$$

where $\Delta$ Voc is the loss in subcell Voc as a result of a loss in that subcell's achievable short circuit current $(\Delta \mathrm{Jsc})$.

The 4-junction solar cell being proposed at several laboratories [4,5] is unique from an AR coating perspective because its spectral range is relatively broad and the device has subcells with bandgaps that are nearly ideal for a 4-junction tandem solar cell. As a result, this solar cell has the potential to be well current matched and will therefore require an AR coating that is equally effective across the entire spectral range. It is the combination of both broadband spectral response and potentially well current matched subcells that places demands on AR coatings which have not previously been necessary. Figure 2 suggests that this solar cell will benefit significantly by improving AR coating technology beyond that of the DLAR coating. All further AR coating performance modeling presented here will therefore be applied to this 4-junction device, which is assumed perfectly current matched in the limiting case of no front reflection.

\section{TRIPLE LAYER ANTI-REFLECTION COATINGS}

A logical approach for improving the performance of currently-used DLAR step-down coatings is to extend the step-down concept with investigation of a TLAR step-down coating. To determine the optimum indices of refraction $\left(n_{H}, n_{M}, n_{L}\right)$ for a TLAR coating in the envisioned 4-junction solar cell, the optical thin film software FTG DESIGN [15] was used to optically model the solar cell structure and determine the device reflectance as a function of the AR coating structure. Equations 1 and 2 were then used to compute the SWR from the modeled reflectance, and arrive at the AR coating layer indices and thicknesses that minimize the SWR. A schematic of the modeled optical structure is shown in Figure 3 , and includes all relevant optical layers. The thickness, dispersive index of refraction $(n)$, and dispersive extinction coefficient $(k)$ for each of the fixed layers were specified from measured, estimated, or previously reported data. The optical constants of the variable AR coating layers were assumed non-dispersive and non-absorptive.

Results of the TLAR optimization are shown in Figure 4. The optimum index for each of the AR coating layers are shown together with the dispersive indices of the glass encapsulant, window layer material, and first subcell material. Also shown are the indices of commonly used DLAR coatings $\mathrm{TiO}_{2}$ and $\mathrm{Al}_{2} \mathrm{O}_{3}$. From Figure 4 it is evident that the index of $\mathrm{TiO}_{2}$ is significantly lower than that of the optimum high index material in a TLAR coating, and the index of $\mathrm{Al}_{2} \mathrm{O}_{3}$ is only slightly lower than that of the optimum low index material. One difficulty in development of an optimum TLAR coating is finding a suitable optical material with a refractive index close to $n_{H}$. To the author's knowledge no optical materials with an index greater than that of $\mathrm{TiO}_{2}$ are known that are also suitably transmissive, have stable optical properties, and can be feasibly deposited in thin film form.

An alternative approach for TLAR coating development is to insert a medium index material in between the conventional $\mathrm{TiO}_{2} / \mathrm{Al}_{2} \mathrm{O}_{3}$ DLAR structure. Although this sub-optimum TLAR coating structure will under-perform the optimum TLAR structure, improvement over the DLAR coating can be expected. An analysis similar to that presented in Figure 4 was conducted to determine the ideal refractive index of the medium index material when sandwiched between $\mathrm{TiO}_{2}$ and $\mathrm{Al}_{2} \mathrm{O}_{3}$. Those results are presented in Figure 5 and suggest an optimum refractive index of 1.95 .

Table 1 lists common optical materials that may be suitable as a medium index material in the TLAR coating due to their near-optimum refractive index. Optical materials must not only have a suitable refractive index but must also be highly transmissive across the entire useable solar spectrum. These materials should also be chemically and mechanically stable in the solar cell environment, with no adhesion difficulty, optical degradation, reaction with other thin film materials, or cracking due to stress. Deposition of these materials should also be compatible with present solar cell production methods. These additional criteria may preclude the use of some or all of the materials listed in Table 1. For example, from experimental measurements of the optical properties of SiO, modeling suggests that this material is too absorptive in the UV to be suitable for multi-junction solar cell applications. 
Table 1 Relevant properties of common medium-index optical materials

\begin{tabular}{|c|c|c|}
\hline material & index [wavelength $(\mathbf{n m})]$ & transparency range $(\mu \mathrm{m})$ \\
\hline $\mathrm{Y}_{2} \mathrm{O}_{3}$ & $1.82[550]$ & $0.25-2$ \\
\hline $\mathrm{Sc}_{2} \mathrm{O}_{3}$ & $1.86[550]$ & $0.35-13$ \\
\hline $\mathrm{La}_{2} \mathrm{O}_{3}$ & $1.95[550]$ & $0.35-2$ \\
\hline $\mathrm{Si}_{3} \mathrm{~N}_{4}[17]$ & $2.0[500]$ & $0.3-2$ \\
\hline $\mathrm{SiO}$ & $2.0[550]$ & $0.6-8$ \\
\hline $\mathrm{HfO}_{2}$ & $2.0[500]$ & $0.22-12$ \\
\hline $\mathrm{ZrO}_{2}$ & $2.1[550]$ & $0.4-7$ \\
\hline
\end{tabular}

Data from [16] uniess otherwise noted

\section{THE USE OF HERPIN EQUIVALENT LAYERS IN ANTI-REFLECTION COATINGS}

In the mathematical treatment of thin film optics, the optical properties of a single thin film or an assembly of thin films can be completely described by the characteristic matrix of that single film or assembly for a given wavelength and angle of incidence [16]. Epstein showed that the characteristic matrix of a symmetrical combination of non-absorbing thin films can be equal to that of a single non-absorbing film [18]. The two structures are then said to be Herpin equivalents, named after the originator who introduced this type of matrix analysis into optics. Herpin equivalent layers are widely used as a design tool in thin film optics because a film with an intermediate refractive index that is unavailable or impractical can be replaced by a symmetrical combination made up of higher and lower index materials. The multilayer has approximately the same total optical thickness and the same equivalent refractive index as the single film. Conversely, the Herpin equivalent concept can be used to reduce a complex multilayer with symmetrical sub-components to a simpler structure, for ease of modeling and design.

The Herpin equivalent layers concept is applied here in a TLAR coating for multi-junction solar cells, as shown schematically in Figure 6 . The medium index film in the TLAR coating is replaced by a symmetrical combination of the high and low index materials that are already used in DLAR coating technology (such as $\mathrm{TiO}_{2}$ and $\mathrm{Al}_{2} \mathrm{O}_{3}$ ). The result is a high/low/high/low index (HLHL), 2-material AR coating that is not of the stepdown variety but approximates the optical performance of a TLAR step-down coating, without the use of a third optical material. Development of a deposition process, characterization of the optical properties, and environmental testing and verification for new materials are therefore avoided.

The Herpin equivalence is a mathematical equivalence of the characteristic matrices, strictly valid at one wavelength and angle of incidence, rather than a true physical equivalence. Modeling was therefore conducted to determine how the closely the HLHL AR coating performance can approximate that of a TLAR step-down coating. The same modeling capabilities used to generate Figures 2, 4 and 5 were used to search for the AR coating designs which resulted in the best performance from these two AR coating structures. The modeled reflectances of the resulting optimized structures are shown in Figure 7, along with the calculated SWR for the 4-junction device. Also shown for comparison are the reflectance and SWR data for an optimized DLAR coating. Optical data for $\mathrm{TiO}_{2}$ and $\mathrm{Al}_{2} \mathrm{O}_{3}$ were used as the high and low index materials, respectively. For the medium index material in the TLAR coating, a non-dispersive refractive index of 1.95 was assumed. It is evident from Figure 7 that the HLHL AR coating results in a device reflectance very similar to that of the TLAR coating, suggesting their near-equivalence. The calculated SWR of the HLHL coating is only slightly greater than that of the optimized TLAR. Both AR coating structures significantly outperform the DLAR coating by over $2.5 \%$ absolute.

A HLHL AR coating structure using $\mathrm{TiO}_{2}$ and $\mathrm{Al}_{2} \mathrm{O}_{3}$ as the high and medium index materials, respectively, was deposited on silicon to demonstrate the ability to deposit this $A R$ coating and to model the experimental reflectance. This provides validity for the modeling results presented thus far and demonstrates the practical feasibility of this AR coating structure. The results are shown in Figure 8. Excellent agreement is evident between the measured and modeled data. The significant divergence between model and 
measurement at long wavelengths is because the optical model assumes planar surfaces, whereas the actual silicon wafer back surface is not specular. This results in a lower escape reflectance for the measured device. The reflectance of the HLHL AR coating shows three local minima, which is characteristic of a step-down TLAR coating. This further verifies the near-equivalence of these two coating structures.

\section{Sensitivity Analysis}

In the Herpin equivalent concept, the combined thickness of the equivalent symmetric multilayer will be similar to that of the original single film. This implies that the symmetric multilayer will consist of relatively thin sub-layers, which may present problems in terms of practical reproducibility. A sensitivity analysis was conducted to compare the relative performance sensitivity of the DLAR, TLAR, and HLHL AR coating structures due to a layer thickness variation. The absolute change in $\%$ SWR exhibited by each of the AR coating structures for both $a+1-2 \mathrm{~nm}$ and $+/-5 \%$ thickness variation is shown in Figure 9 . It is evident that the TLAR is slightly less sensitive to thickness variations than the DLAR, but the HLHL AR coating is more sensitive than either of the simpler structures. Although both the TLAR and HLHL AR coatings still outperform the DLAR coating even with these reproducibility limits, the accuracy and reproducibility of deposition equipment needs to be considered when evaluating the feasibility of implementing the HLHL AR coating as an alternative to the step-down TLAR coating.

\section{CONCLUSIONS}

Modeling has suggested that future high efficiency 4-junction solar cells will benefit significantly from the development of AR coatings that perform better than current double layer AR coating technology. The triple layer AR coating is a logical avenue for pursuing this higher performance. A new AR coating structure based on the use of Herpin equivalent layers has been presented. This structure requires no additional optical material development and characterization because no new optical materials are necessary. The optical structure is a high/low/high/low index combination of the same materials used in the double layer AR coating. This reduces the development time associated with improving AR coating performance. Experimental results suggest good agreement with modeling and have demonstrated feasibility of the new AR coating. Sensitivity analysis suggests that the new coating is slightly more sensitive to thickness variations.

\section{REFERENCES}

[1] M.A. Green, K. Emery, K. Bucher, D.L. King, S. Igari, "Solar Cell Efficiency Tables (Version 11)", Progress in Photovoltaics, vol. 6, pp. 35-42, 1998.

[2] T. Takamoto, M. Yamaguchi, S.J. Taylor, E. Ikeda, T. Agui, H. Kurita, "High-Efficiency Radiation Resistant InGaP/GaAs Tandem Solar Cells", Proceedings of the $26^{\text {th }}$ IEEE PVSC, pp. 887, 890, 1997.

[3] N.H. Karam, R.R. King, B.T. Cavicchi, D.D. Krut, J.H. Ermer, M. Haddad, L. Cai, D.E. Joslin, M. Takahashi, J.W. Eldredge, W.T. Nishikawa, D.R. Lillington, B.M. Keyes, R.K. Ahrenkiel, "Development and Characterization of High-Efficiency $\mathrm{Ga}_{0.5} \mathrm{In}_{0.5} \mathrm{P} / \mathrm{GaAs} / \mathrm{Ge}$ Dual- and Triple-Junction Solar Cells", IEEE Transactions on Electron Devices, vol. 46, pp. 2116-2125, 1999.

[4] H. Hou, K. Reinhardt, S. Kurtz, J. Gee, A. Allerman, B. Hammons, P. Chang, E. Jones, "Novel inGaAsN pn Junction for High-Efficiency Multiple-Junction Solar Cells", $2^{\text {nd }}$ World Conference on PV Energy Conversion, (1998), pp. 3600-3603.

[5] D. Friedman, J. Geisz, S. Kurtz, J. Olson, "1-eV GalnNAs Solar Cells for Ultra High Efficiency Multijunction Devices", $2^{\text {nd }}$ World Conference on PV Energy Conversion, (1998), pp. 3-7.

[6] C.H. Henry, "Limiting Efficiencies of Ideal Single and Multiple Energy Gap Terrestrial Solar Cells", Journal of Applied Physics, vol 51, pp. 4494-4500, 1980. 
[7] J.M. Gee, H.L. Tardy, T.D. Hund, R. Gordon, H. Liang, Reflectance Control for Multi-crystalline Silicon Photovoltaic Modules using Textured Dielectric Coatings" Proceedings of First WCPEC, pp. 1274-1277, 1994.

[8] P. Campbell, S.R. Wenham, M.A. Green, "Light Trapping and Reflection Control with Tilted Pyramids and Grooves",Proceedings of $20^{\text {th }}$ IEEE PVSC, pp. 713-716, 1988.

[9] S.H. Zaidi, S.R.J. Brueck, "Si Texturing with Sub-Wavelength Structures", Proceedings of $26^{\text {th }}$ IEEE PVSC, pp. 171-174, 1997.

[10] G.A. Neuman, "'Anti-Reflective Coatings by APCVD using Graded Index Layers", Journal of NonCrystalline Solids, volume 218, pp. 92-99, 1997.

[11] M.J. Minot, "Single-Layer, Gradient Refractive Index Antireflection Films Effective from 0.35 to $2.5 \mu \mathrm{m}$ ", Journal of the Optical Society of America, volume 66, pp. 515-519, 1976.

[12] W.H. Southwell, “Gradient-Index Antireflection Coatings”, Optics Letters, vol.8, pp. 584-585, 1983.

[13] D. Redfield, "Method for Evaluation of Antireflection Coatings", Solar Cells, vol. 3(1981), pp. 27-33.

[14] D.J. Aiken, "Anti-reflection Coating Design for Multi-Junction, Series Interconnected Solar Cells", Proceedings of the $16^{\text {th }}$ Space Photovoltaics Research and Technology conference, to be published.

[15] FILMSTAR DESIGN, version 2.0 from FTG Software Associates, P.O. Box 579, Princeton, N.J. 08542.

[16] H.A. MacLeod, Thin Film Optical Filters, McGraw-Hill, 1989.

[17] E.D. Palik, Handbook of Optical Constants of Solids, Academic Press, Boston, 1991.

[18] L.I. Epstein, "The Design of Optical Filters", Journal of the Optical Society of America, vol. 42, pp. 806810, 1952. 


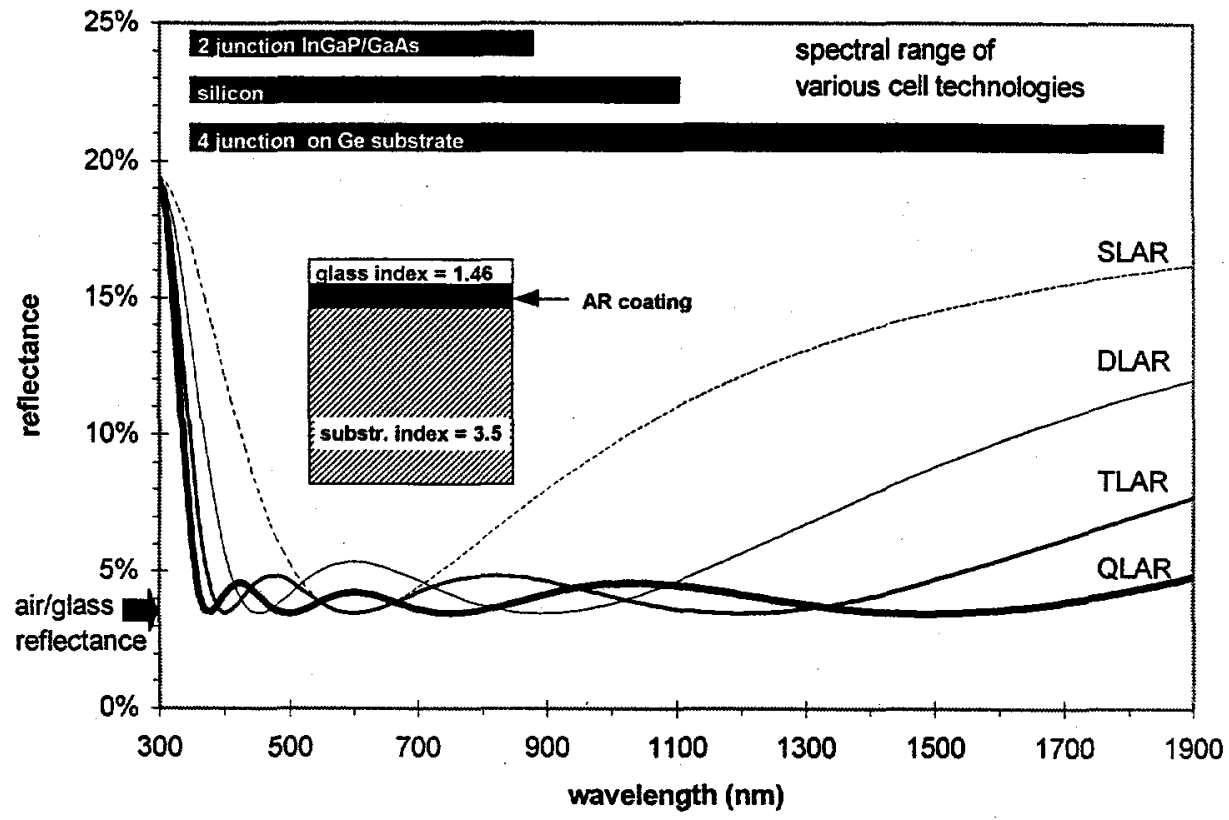

Figure 1 The reflectances of several ideal step-down AR coatings as compared to the spectral range of several high efficiency solar cell technologies. 


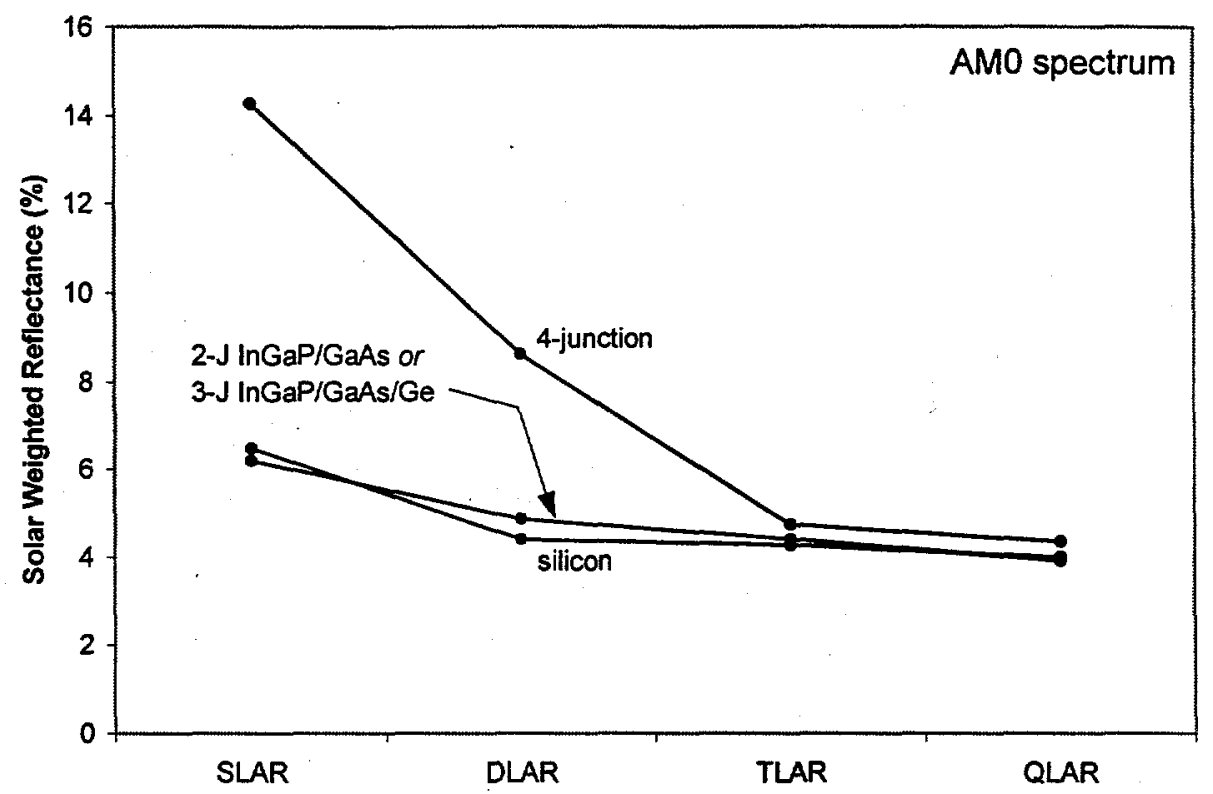

Figure 2 Computed solar weighted reflectance (SWR) for several high efficiency solar cells as a function of the AR coating technologies whose reflectances are shown in Figure 1. 


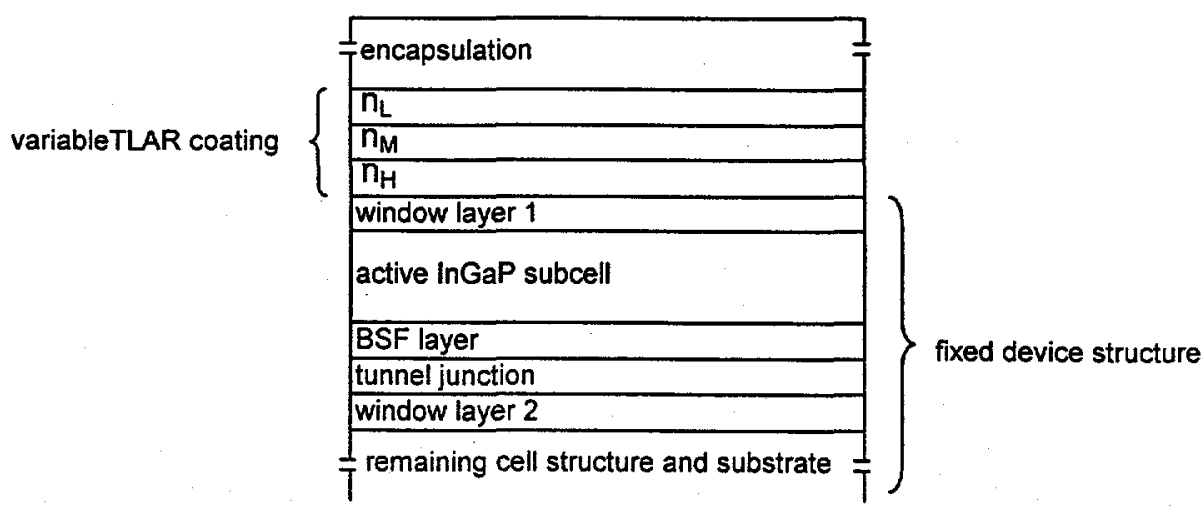

Figure 3 Partial schematic of the optical model of a 4-junction solar cell structure as used in this work. 


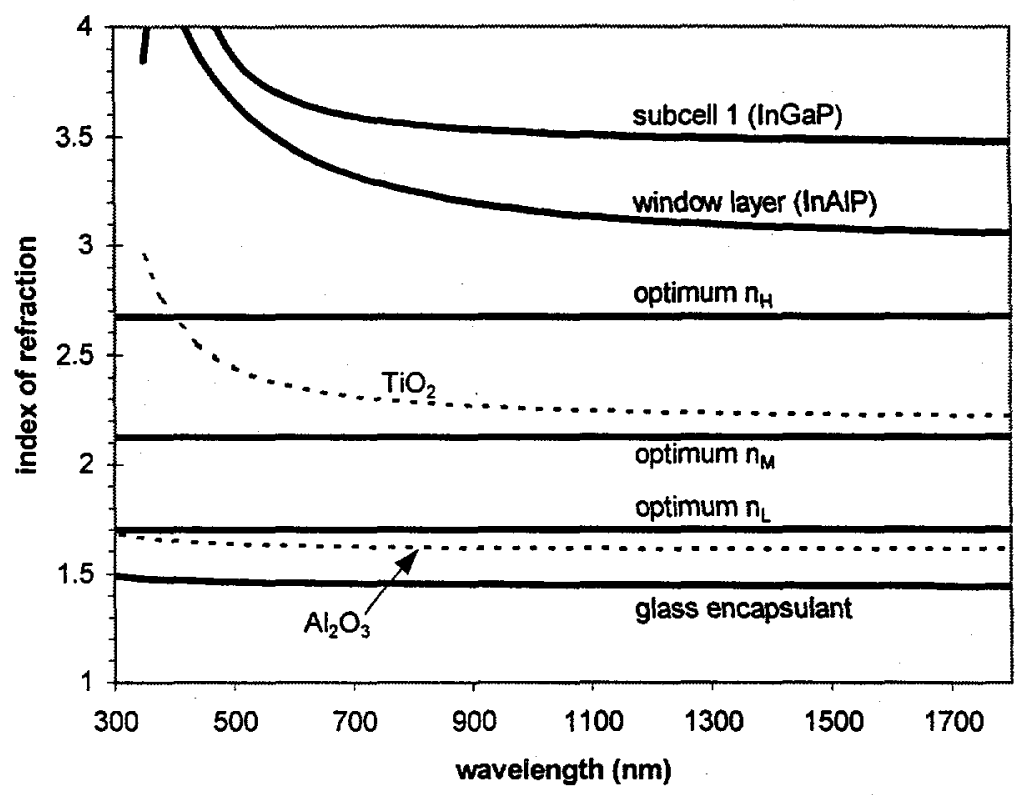

Figure 4 The optimum indices of refraction for a triple layer AR coating structure on a particular III-V 4-junction device, with indices of typically used optical films $\mathrm{TiO}_{2}$ and $\mathrm{Al}_{2} \mathrm{O}_{3}$ shown for comparison. 


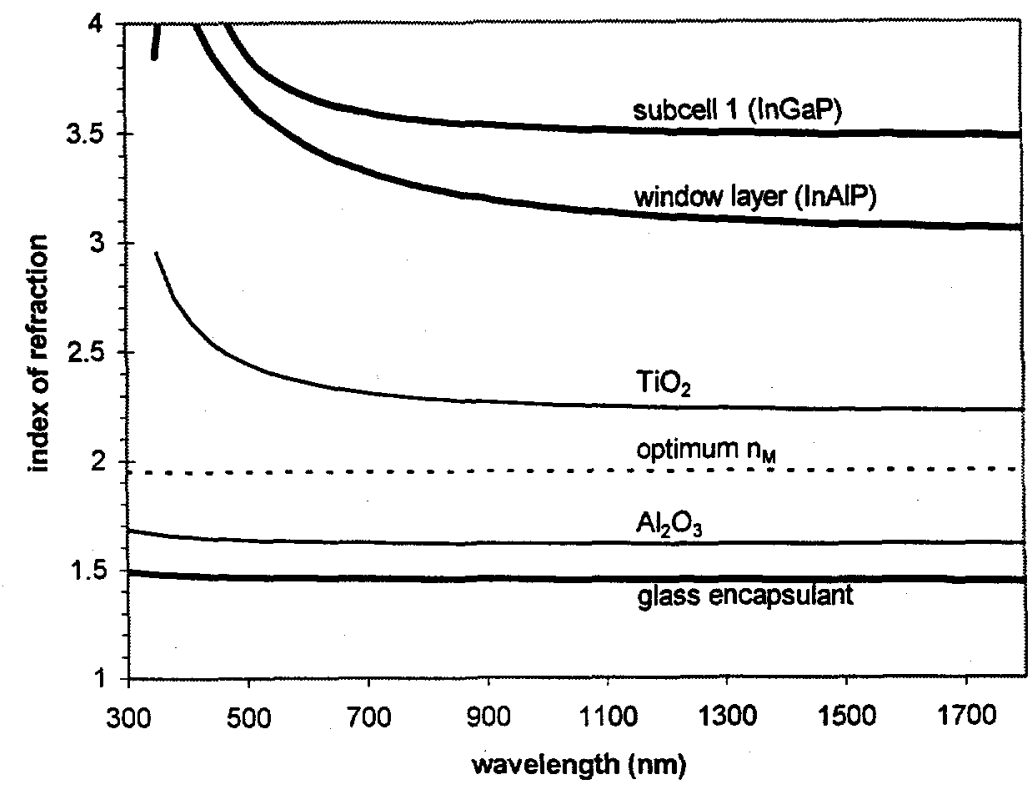

Figure 5 The optimum refractive index for the medium index material in a triple layer AR coating that uses $\mathrm{TiO}_{2}$ and $\mathrm{Al}_{2} \mathrm{O}_{3}$ as the high and low index materials. 


\section{"Step-down" TLAR coating}<smiles>[C]1CCCC1</smiles>
Herpin
equivalent

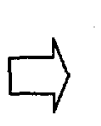

4-layer, 2-material AR coating

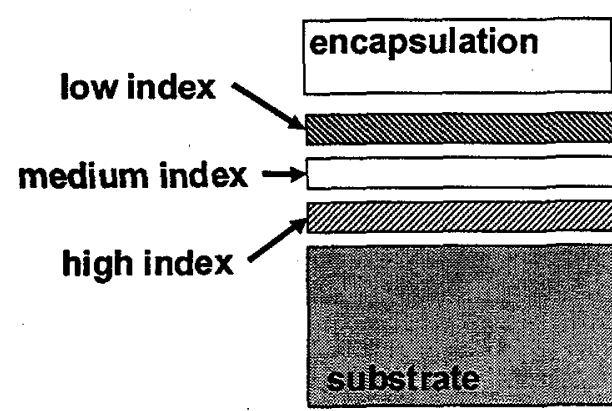

encapsulation

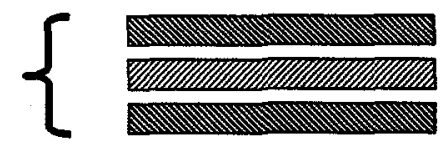

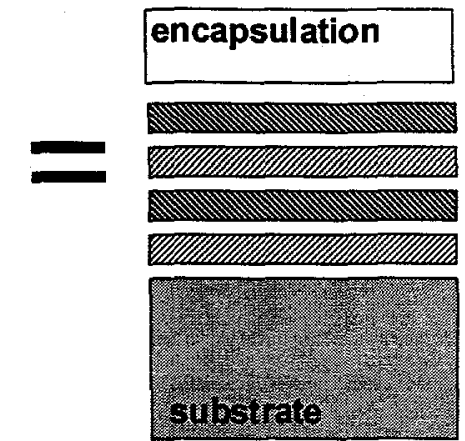

Figure 6 A schematic illustrating the high/low/high/low index AR coating structure as derived from a TLAR structure using the Herpin equivalent concept. 


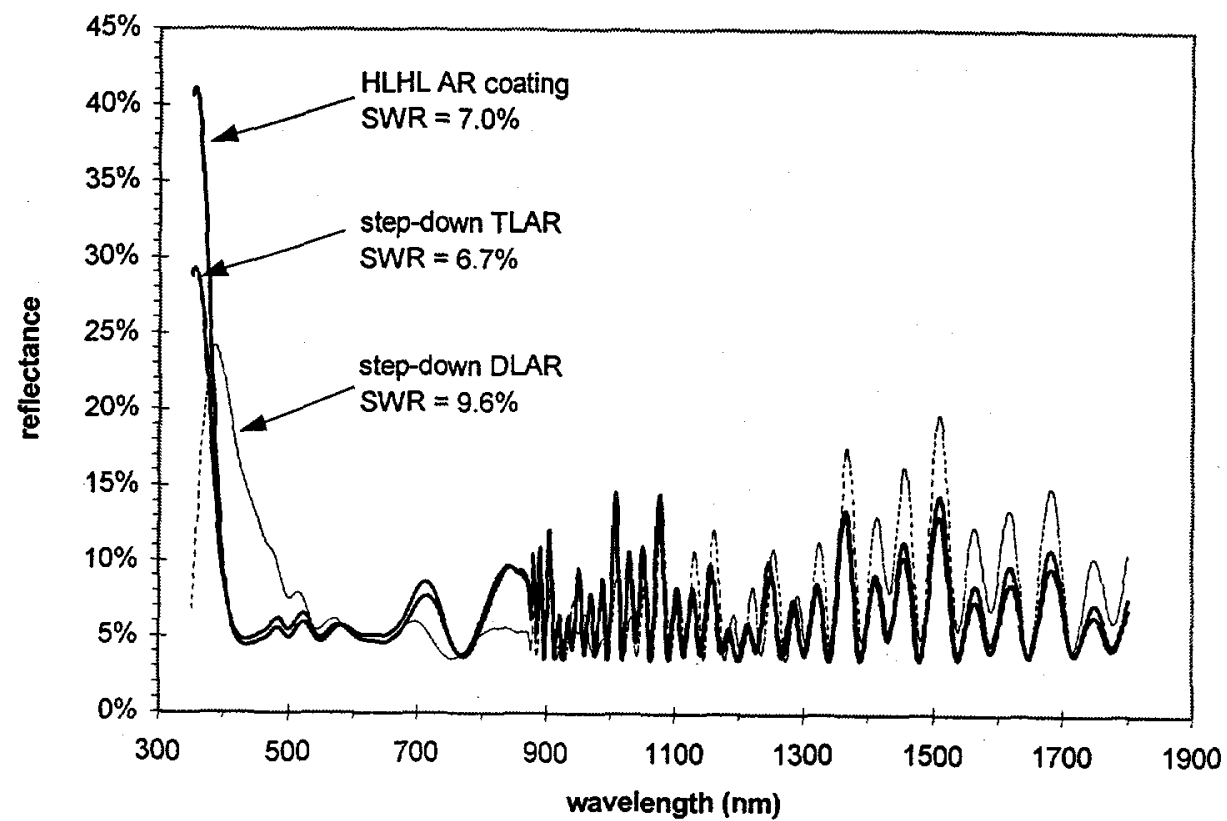

Figure 7 A comparison of the modeled reflectances and computed SWR of three different AR coating structures. 


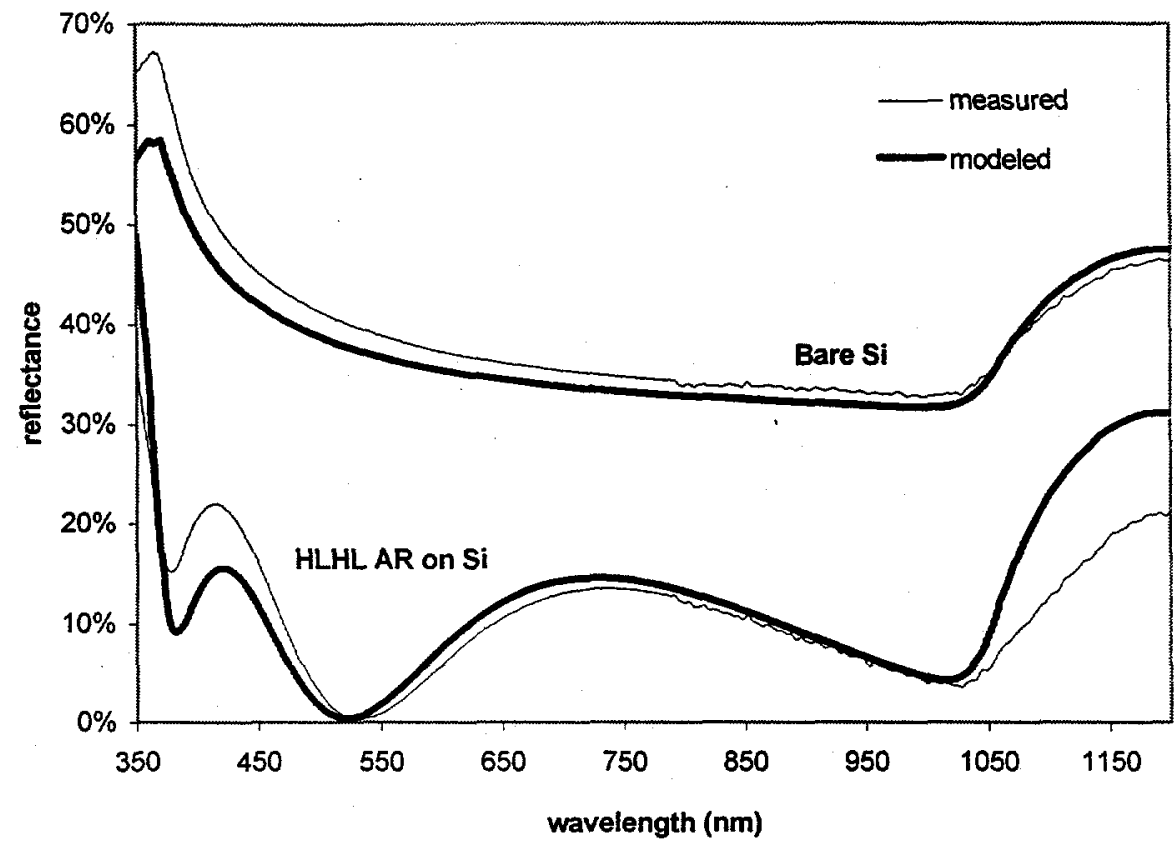

Figure 8 Comparison of measured and modeled reflectances for a HLHL AR coating structure deposited on silicon. 


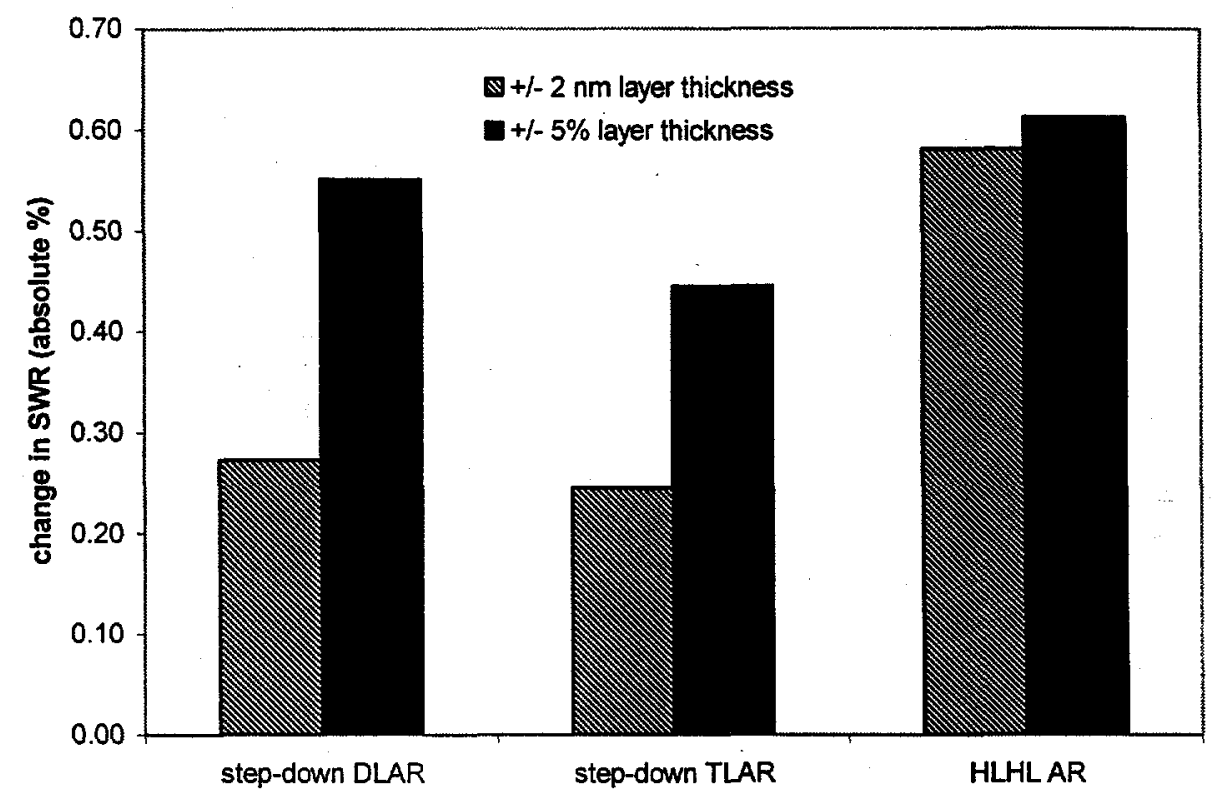

Figure 9 A thickness sensitivity analysis for three different AR coating technologies. 